Article

\title{
Investigation of Sulfonated Graphene Oxide as the Base Material for Novel Proton Exchange Membranes
}

\author{
Andrea Basso Peressut ${ }^{1}\left(\mathbb{D}\right.$, , Matteo Di Virgilio ${ }^{1, * \mathbb{D}}$, Antonella Bombino ${ }^{1}$, Saverio Latorrata ${ }^{1}$, Esa Muurinen ${ }^{2}$, \\ Riitta L. Keiski ${ }^{2}$ (D) and Giovanni Dotelli ${ }^{1, *(D)}$ \\ 1 Department of Chemistry, Materials and Chemical Engineering "Giulio Natta", Politecnico di Milano, \\ Piazza Leonardo da Vinci 32, 20133 Milano, Italy; andreastefano.basso@polimi.it (A.B.P.); \\ antonella.bombino@mail.polimi.it (A.B.); saverio.latorrata@polimi.it (S.L.) \\ 2 Environmental and Chemical Engineering Research Unit, Faculty of Technology, University of Oulu, \\ Pentti Kaiteran katu 1, FI-90014 Oulu, Finland; esa.muurinen@oulu.fi (E.M.); riitta.keiski@oulu.fi (R.L.K.) \\ * Correspondence: matteo.divirgilio@polimi.it (M.D.V.); giovanni.dotelli@polimi.it (G.D.)
}

Citation: Basso Peressut, A.; Di Virgilio, M.; Bombino, A.; Latorrata, S.; Muurinen, E.; Keiski, R.L.; Dotelli, G. Investigation of Sulfonated Graphene Oxide as the Base Material for Novel Proton Exchange Membranes. Molecules 2022, 27, 1507. https://doi.org/ 10.3390/molecules 27051507

Academic Editors: Crina Socaci, Mihaela Diana Lazar and Maria Mihet

Received: 1 February 2022

Accepted: 22 February 2022

Published: 23 February 2022

Publisher's Note: MDPI stays neutral with regard to jurisdictional claims in published maps and institutional affiliations.

Copyright: (C) 2022 by the authors. Licensee MDPI, Basel, Switzerland. This article is an open access article distributed under the terms and conditions of the Creative Commons Attribution (CC BY) license (https:// creativecommons.org/licenses/by/ $4.0 /)$.

\begin{abstract}
This work deals with the development of graphene oxide (GO)-based self-assembling membranes as possible innovative proton conductors to be used in polymer electrolyte membrane fuel cells (PEMFCs). Nowadays, the most adopted electrolyte is Chemours' Nafion; however, it reveals significant deficiencies such as strong dehydration at high temperature and low humidity, which drastically reduces its proton conductivity. The presence of oxygenated moieties in the GO framework makes it suitable for functionalization, which is required to enhance the promising, but insufficient, proton-carrying features of GO. In this study, sulfonic acid groups $\left(-\mathrm{SO}_{3} \mathrm{H}\right)$ that should favor proton transport were introduced in the membrane structure via a reaction between GO and concentrated sulfuric acid. Six acid-to-GO molar ratios were adopted in the synthesis procedure, giving rise to final products with different sulfonation degrees. All the prepared samples were characterized by means of TGA, ATR-FTIR and Raman spectroscopy, temperature-dependent XRD, SEM and EDX, which pointed out morphological and microstructural changes resulting from the functionalization stage, confirming its effectiveness. Regarding functional features, electrochemical impedance spectroscopy (EIS) as well as measurements of ion exchange capacity (IEC) were carried out to describe the behavior of the various samples, with pristine GO and commercial Nafion ${ }^{\circledR} 212$ used as reference. EIS tests were performed at five different temperatures $\left(20,40,60,80\right.$ and $\left.100{ }^{\circ} \mathrm{C}\right)$ under high (95\%) and medium (42\%) relative humidity conditions. Compared to both GO and Nafion ${ }^{\circledR} 212$, the sulfonated specimens demonstrate an increase in the number of ion-carrying groups, as proved by both IEC and EIS tests, which reveal the enhanced proton conductivity of these novel membranes. Specifically, an acid-to-GO molar ratio of 10 produces a six-fold improvement of IEC $\left(4.23 \mathrm{meq}^{-1}\right)$ with respect to pure GO $\left(0.76 \mathrm{meq}^{-1}\right)$, while a maximum eight-fold improvement $\left(5.72 \mathrm{meq}^{-1}\right)$ is achieved in SGO-15.
\end{abstract}

Keywords: self-assembling membranes; graphene oxide; sulfonation; proton conductors; XRD; IEC

\section{Introduction}

Nowadays, graphene oxide (GO) is considered among the most attractive graphenerelated materials. It can be described with good approximation as a one-atom-thick twodimensional sheet of carbon atoms arranged in a texture similar to a honeycomb. The carbon atoms can be $\mathrm{sp}^{2}$ - or $\mathrm{sp}^{3}$-hybridized and form chemical bonds with oxygenated functionalities. The most important are hydroxyl $(-\mathrm{OH})$, epoxy $(\mathrm{C}-\mathrm{O}-\mathrm{C})$ and carbonyl $(\mathrm{C}=\mathrm{O})$ groups, which are mainly located on the basal plane, and carboxyl $(-\mathrm{COOH})$ and phenolate $(-\mathrm{OPh})$ ones, whose steric hindrance compels their positioning at the sheet edges [1-3]. The random distribution of these moieties causes a nonstoichiometric atomic composition; therefore, a univocal molecular structure of GO is still under debate inasmuch as several 
preparation factors can directly influence it, such as the graphite source, the oxidizing agent and the reaction conditions. However, the presence of oxygenated functionalities endows GO with an amphiphilic nature that explains its dispersibility in aqueous media. The compresence of $\pi$-conjugated hydrophobic and aliphatic hydrophilic domains is one of the main reasons for the interesting self-assembling ability of this carbon-based material, which can stack to form large and thin free-standing paper-like membranes [4]. Other fascinating physicochemical properties derive from such a configuration, i.e., high mechanical strength, high acidity, variable electrical conductivity depending on the oxidation degree and intrinsic chemical reactivity [3-5]. The versatility of GO is in fact exploited in a wide range of applications, such as wastewater treatment [6,7], acid catalysis [8], power generation [9] and supercapacitors [10].

As a consequence of its high surface reactivity, GO structure can be easily tuned by performing an alteration of the oxygenated groups content or a convenient functionalization [2,4]. The purpose is the obtainment of derivatives with properties able to fulfill the specifications of those devices in which pure GO would not be sufficiently suitable. Reduced graphene oxide (rGO) and sulfonated graphene oxide (SGO) represent a clear example of such modifications. The former is prepared via a thermal or chemical reduction with the intent of increasing the C-to-O ratio up to values approaching pristine graphene [5], and finding employment in Li-ion batteries [11] and filters for water softening [6]. The latter is characterized by sulfonic acid groups grafted on the GO surface, which bestow a high ionic conductivity thanks to the facilitated solvation of movable protons [12], and it is mainly applied in the field of fuel cells [13-18].

Several authors have focused on researching an adequate sulfonation method to prepare SGO for fuel cell-related applications. Its typical employment is as an addition to electrolytes with the aim of enhancing water retention, proton conduction and mechanical properties. Zarrin et al. [15] studied SGO/Nafion ${ }^{\circledR}$ nanocomposites as a potential replacement of unmodified Nafion ${ }^{\circledR}$ in polymer electrolyte membrane fuel cells working at high temperature. They functionalized GO by reacting it with 3-mercaptopropyl trimethoxysilane (MPTMS) in toluene at $110{ }^{\circ} \mathrm{C}$ for $24 \mathrm{~h}$ and then oxidizing the intermediate at $25^{\circ} \mathrm{C}$ for $24 \mathrm{~h}$ with a $30 \mathrm{wt} . \%$ solution of hydrogen peroxide $\left(\mathrm{H}_{2} \mathrm{O}_{2}\right)$. The composite membranes, fabricated via the solution casting, demonstrated a significant enhancement in proton conductivity with respect to untreated Nafion ${ }^{\circledR}$. The same material was proposed by Chien et al. [16] for high-performance direct methanol fuel cells. However, they employed a different precursor to prepare SGO, that is, sulfanilic acid. They added GO to a $0.06 \mathrm{M}$ solution of sulfanilic acid at $70{ }^{\circ} \mathrm{C}$, then dripped a $0.006 \mathrm{M}$ sodium nitrite $\left(\mathrm{NaNO}_{2}\right)$ solution under continuous stirring, maintaining the mixture at $70^{\circ} \mathrm{C}$ for $12 \mathrm{~h}$. The resulting $\mathrm{SGO} / \mathrm{Nafion}{ }^{\circledR}$ proton exchange membranes, manufactured by bar coating, displayed a low methanol crossover and high proton conductivity at a low relative humidity. Li et al. [17] analyzed a sulfonated holey graphene oxide paper sandwiched between two sulfonated poly(ether ether ketone) (SPEEK) membranes. SGO was prepared by the combination of $\mathrm{GO}$ with an arenediazonium salt synthetized from sulfanilic acid, hydrochloric acid $(\mathrm{HCl})$, $\mathrm{NaNO}_{2}$ and sodium hydroxide $(\mathrm{NaOH})$. The performance of the combined materials was satisfactory from the point of view of proton exchange. Vinothkannan et al. [18] evaluated the practicability of $\mathrm{SGO}-\mathrm{Fe}_{3} \mathrm{O}_{4}$-filled Nafion ${ }^{\circledR}$ in proton exchange membrane fuel cells working at low humidity. SGO was obtained via a reaction with an aryldiazonium salt of sulfanilic acid in an ice bath, whereas the composite membranes were produced via solution casting. They observed the positive influence of SGO on the functional properties of Nafion ${ }^{\circledR}$, stating the possibility of implementation in real devices. Despite such premises, the danger of some reactants required for SGO preparation and the difficulty to free them from the coupling with a polymeric matrix are still unsolved issues.

This work concerns the preparation and detailed study of self-assembling sulfonated graphene oxide (SGO-X) membranes as a potential base material for novel proton conductors to be employed in proton exchange membrane fuel cells (PEMFCs). The core of the procedure is the controlled reaction between $\mathrm{GO}$ and concentrated sulfuric acid aimed 
at decorating the $\mathrm{GO}$ framework with sulfonic acid groups $\left(-\mathrm{SO}_{3} \mathrm{H}\right)$, thereby favoring proton transport. Six acid-to-GO molar ratios $(X=1,2.5,5,10,15,20)$ were explored to comprehend the effects of such a procedure on the morphology and properties of a GO structure. The corresponding SGO-X samples were extensively characterized via a thermogravimetric analysis (TGA), attenuated total reflection Fourier transform infrared (ATR-FTIR) and Raman spectroscopies, temperature-dependent $\mathrm{X}$-ray diffraction (XRD), scanning electron microscopy (SEM) and energy-dispersive X-ray (EDX) spectroscopy. Furthermore, functional properties were preliminarily evaluated by means of ex situ ion exchange capacity (IEC) and electrochemical impedance spectroscopy (EIS) tests, in order to assess the suitability of this material for possible in situ experiments. A comparison was conducted with pure GO and Nafion ${ }^{\circledR} 212$, which was taken as an example of the industry-leading proton conductors' family, with the aim of determining the potentiality of SGO-X membranes as innovative materials for the electrochemical energy generation sector.

\section{Materials and Methods}

\subsection{Materials}

Graphene oxide was purchased from Graphenea, Inc. (Cambridge, MA, USA) as a $0.4 \mathrm{wt} . \%$ aqueous dispersion with average particle size of less than $10 \mu \mathrm{m}$ and a pH between 2.2 and 2.5. Starting from an elemental analysis performed by the vendor [19], the authors extrapolated an empirical GO formula $\left(\mathrm{C}_{1.5} \mathrm{H}_{0.2} \mathrm{~N}_{0.01} \mathrm{~S}_{0.03} \mathrm{O}\right)$ by exploiting the oxygen atoms content as normalization factor [14]. The associated molecular mass of $35.3 \mathrm{~g} \mathrm{~mol}^{-1}$ was compatible with literature values $[20,21]$ and preliminary energy dispersive X-ray (EDX) analyses executed on a pristine sample [14].

Durapore ${ }^{\circledR}$ polyvinylidene fluoride (PVDF) filter disks with a thickness of $125 \mu \mathrm{m}$ and a pore size of $0.22 \mu \mathrm{m}$ were purchased from Merck Millipore (Burlington, MA, USA).

Concentrated sulfuric acid (ACS reagent) with a purity of $95.0-97.0 \%$, sodium chloride (ACS reagent) with a purity of $\geq 99.0 \%$ and sodium hydroxide pellets (ACS reagent) with a purity of $\geq 97.0 \%$ were acquired from Sigma-Aldrich Corporation.

The same supplier also provided Nafion ${ }^{\circledR} 212$ as a $30 \mathrm{~cm} \times 30 \mathrm{~cm}$ polymeric sheet protected by two films that shielded the material from undesired contacts with the environment, so as to preserve its properties. It displayed a thickness of $50.8 \mu \mathrm{m}$ and an equivalent weight of $2100 \mathrm{~g} \mathrm{eq}^{-1}$.

\subsection{Membranes Preparation}

The manufacturing procedure of sulfonated graphene oxide samples initially involved a 15-min ultrasonication of $150 \mathrm{~mL}$ of the GO aqueous dispersion (600 $\mathrm{mg}$ of GO) placed in a round-bottomed flask, aimed at improving the overall homogeneity of the material. For this purpose, the Falc Instruments s.r.l. (Treviglio, Italy) ultrasound bath LABSONIC LBS 1-H3, ice-refrigerated to control the system temperature and, therefore, to avoid undesired overheating and thermal reduction, was used. After this step, an appropriate quantity of sulfuric acid was slowly incorporated in the flask, which was, subsequently, dipped into an oil bath and assembled with a reflux condenser and a magnetic stirrer. The functionalization process duration was six hours, the first three of which were carried out at ambient temperature $\left(25^{\circ} \mathrm{C}\right)$ and the remaining three at high temperature $\left(100{ }^{\circ} \mathrm{C}\right)$. Magnetic mixing at $1500 \mathrm{rpm}$ was applied during the entire functionalization timespan to guarantee a continuous homogenization of the dispersion. Dilution of the so-treated mixture, performed by means of $400 \mathrm{~mL}$ of deionized water, allowed an increase in $\mathrm{pH}$ up to values that could prevent problems during the subsequent filtration phase. In such step, the dispersion was vacuum-filtered on a PVDF filter disk placed on a Büchner funnel $(14 \mathrm{~cm}$ in diameter) to drain the slurry and deposit the material. Additional $200 \mathrm{~mL}$ of deionized water was poured over the settling mixture in a controlled fashion in order to promote the removal of unreacted excess acid. In the end, the deposit was dried in an oven at $40{ }^{\circ} \mathrm{C}$ to favor the evaporation of water residues and conclude the self-assembly of the final product. 
Six samples were prepared in this work by adopting different acid-to-GO molar ratios, namely, 1, 2.5, 5, 10, 15 and 20, a range that was identified as the most promising one in a previous work by the authors [14]. The GO molecular mass discussed in Section 2.1 was employed to evaluate the corresponding required acid volumes, as summarized in Table 1. The nomenclature chosen for the samples was SGO- $X$, in which $X$ represented their specific acid-to-GO molar ratio.

Table 1. Sulfuric acid quantities used to produce the six SGO-X samples.

\begin{tabular}{cccc}
\hline Sample & $\begin{array}{c}\text { Acid-to-GO } \\
\text { Molar Ratio }\end{array}$ & $\begin{array}{c}\text { Moles of Acid } \\
(\mathbf{m o l})\end{array}$ & $\begin{array}{c}\text { Volume of Acid } \\
(\mathbf{m L})\end{array}$ \\
\hline SGO-1 & 1 & 0.017 & 0.90 \\
SGO-2.5 & 2.5 & 0.042 & 2.25 \\
SGO-5 & 5 & 0.085 & 4.50 \\
SGO-10 & 10 & 0.170 & 9.00 \\
SGO-15 & 15 & 0.255 & 13.50 \\
SGO-20 & 20 & 0.340 & 18.00 \\
\hline
\end{tabular}

A virgin GO sample was also prepared to be considered as a reference, starting from the same volume of $150 \mathrm{~mL}$ of commercial aqueous dispersion (600 mg of GO) ultrasonicated for $15 \mathrm{~min}$ in the presence of ice to mitigate the temperature increase. Vacuum-filtration and successive oven-drying at $40^{\circ} \mathrm{C}$ allowed to complete the fabrication of the GO membrane.

\subsection{Morphological and Microstructural Characterization}

Thermogravimetric analysis (TGA) was executed through the Seiko Instruments Inc. EXSTAR 6000 TG/DTA 6300 by increasing the temperature from room conditions to $1000{ }^{\circ} \mathrm{C}$ via a heating ramp of $10{ }^{\circ} \mathrm{C} \mathrm{min}^{-1}$. The chamber atmosphere was maintained inert by providing pure nitrogen at a flow rate of $55 \mathrm{~mL} \mathrm{~min}^{-1}$.

The ThermoElectron Continu $\mu$ m IR microscope, combined with an FTIR Nicolet Nexus spectrometer, both provided by Thermo Fisher Scientific Inc. (Rodano, Italy), was used to acquire attenuated total reflection Fourier transform infrared (ATR-FTIR) spectra of the fabricated SGO-X membranes, along with those of benchmark GO, within a wavenumbers' interval of $650-4000 \mathrm{~cm}^{-1}$. The experimental setup was created out of a single reflection silicon crystal and a mercury cadmium telluride (MCT) detector cooled by liquid nitrogen. A number of scans equal to 128 and a resolution of $4 \mathrm{~cm}^{-1}$ were applied during the execution of the tests.

Raman spectroscopy was performed by means of the Jobin Yvon LabRAM HR800 spectrometer by HORIBA (Kyoto, Kyoto), which was coupled with a 50x-objective Olympus BX41 microscope. The tests were conducted in a micro-Raman setup: the exciting source was a helium-neon (He-Ne) laser characterized by a wavelength of $632.8 \mathrm{~nm}$, whose power was limited to $500 \mu \mathrm{W}$ to minimize possible degradation and heating issues of the investigated materials.

X-ray diffraction (XRD) analysis was performed on all the as-prepared samples to infer information on their structural arrangement and stability as a function of temperature. Four subsequent conditions were implemented-30,60, $120{ }^{\circ} \mathrm{C}$ and the cooled state-; the latter was reached after decreasing the specimens' temperature from $120^{\circ} \mathrm{C}$ to $30^{\circ} \mathrm{C}$. The temperature transitions were achieved at a heating rate of $10^{\circ} \mathrm{C} \mathrm{min}{ }^{-1}$, followed by a 5-min holding before starting the measurements. The Rigaku SmartLab $9 \mathrm{~kW}$, equipped with the Anton Paar DHS1100 high-temperature furnace and a D/teX Ultra 250 detector, was exploited for the described experiments. A cobalt (Co) filament was implemented as an X-ray source with a wavelength $(\lambda)$ of $0.179 \mathrm{~nm}$. An angular range $(2 \theta)$ of $5-30^{\circ}$ was covered during the tests with a step width of $0.02^{\circ}$ and a scanning rate of $0.05^{\circ} \mathrm{s}^{-1}$. 
Interplanar distances $d(\mathrm{~nm})$ were calculated by means of Bragg's law (Equation (1)) at the angle of incidence $\theta\left(^{\circ}\right)$ associated with sharp reflections:

$$
\mathrm{d}(\mathrm{nm})=\frac{\lambda}{2 \sin \theta}
$$

The Stereoscan 360 microscope, supplied by Cambridge Scientific Instrument Co. (Cambridge, UK), allowed the acquisition of scanning electron microscopy (SEM) images at $100 \times$ and $1000 \times$ magnifications. Accelerating voltage and current probe were set to $20 \mathrm{kV}$ and $200 \mathrm{pA}$, respectively, and the chamber was operated under vacuum conditions. The apparatus employed for energy dispersive X-ray (EDX) spectroscopy experiments comprised of the scanning electron microscope model EVO 50 EP by Carl Zeiss AG and the INCA 200 PENTAFET LZ4 EDX spectrometer by Oxford Instruments plc. The accelerating voltage was $20 \mathrm{kV}$, the maximum current probe was $100 \mathrm{pA}$, and the pressure was kept in the range of 30-40 Pa. EDX measurements were carried out at $500 \times$ magnification on different zones of each sample; therefore, averaged compositional results were obtained.

\subsection{Ion Exchange Capacity Evaluation}

Ion exchange capacity (IEC) was assessed to define the role of sulfonic acid groups $\left(-\mathrm{SO}_{3} \mathrm{H}\right)$ in the ionic conduction mechanism of SGO-X samples by comparing their performance with the ones of pristine GO and Nafion ${ }^{\circledR}$ 212. A classical acid-base titration method was executed, replicating a technique already exploited by the authors in previous works [14,22]. Firstly, the samples were dried in oven at $60^{\circ} \mathrm{C}$ for $1 \mathrm{~h}$ and their dry mass was measured. Afterwards, they were equilibrated at room temperature in $250 \mathrm{~mL}$ of a $2 \mathrm{M}$ sodium chloride $(\mathrm{NaCl})$ aqueous solution for $48 \mathrm{~h}$ to allow the exchange of $\mathrm{H}^{+}$ions, belonging to both oxygenated and sulfonated regions, with $\mathrm{Na}^{+}$provided by the dissolved salt. After the equilibration time, the membrane portions were taken away and small volumes of a $0.01 \mathrm{M}$ sodium hydroxide $(\mathrm{NaOH})$ aqueous solution were used to titrate the original $\mathrm{NaCl}$ one. At each addition, the $\mathrm{pH}$ variation was recorded via the METTER TOLEDO ${ }^{\circledR} \mathrm{MP} 220$ Basic $\mathrm{pH} / \mathrm{mV} /{ }^{\circ} \mathrm{C}$ Meter in order to build the $\mathrm{V}_{\mathrm{NaOH}}-\mathrm{pH}$ titration curves and determine the turning point values. IEC, which represents the milliequivalents of ionic sites containing exchangeable protons per gram of dried sample, was computed via Equation (2) as a function of the volume of $\mathrm{NaOH}$ solution $\mathrm{V}_{\mathrm{NaOH}}(\mathrm{mL})$ required to reach the turning point, its concentration $\mathrm{C}_{\mathrm{NaOH}}\left(\mathrm{mmol} \mathrm{mL}^{-1}\right)$ and the dry mass of the samples $\mathrm{m}_{\text {dry }}(\mathrm{g})$ :

$$
\operatorname{IEC}\left(\text { meq }^{-1}\right)=\frac{\mathrm{V}_{\mathrm{NaOH}} \cdot \mathrm{C}_{\mathrm{NaOH}}}{\mathrm{m}_{\mathrm{dry}}}
$$

\subsection{Proton Conductivity Investigation}

The experimental setup exploited for the proton conductivity quantification via electrochemical impedance spectroscopy (EIS) comprised of a humid chamber designed to maintain the desired temperature and relative humidity $(\mathrm{RH})$ levels for a total of ten combinations given by five different temperatures $\left(20,40,60,80,100{ }^{\circ} \mathrm{C}\right)$ and two $\mathrm{RH}$ values $(95 \%$ and $42 \%$ ). Temperature was controlled by circulating heated oil through the outer jacket of the chamber and by inserting a thermocouple inside it. The thermohygrometer model C3121 by Comet System s.r.o. equipped with an external probe was employed to check the correct achievement of the RH values. The samples, previously trimmed in the shape of rectangles, underwent width and thickness measurements after being dried in an oven at $60{ }^{\circ} \mathrm{C}$ for $2 \mathrm{~h}$. Then, they were clamped on a Teflon ${ }^{\circledR}$ cell between two stainless-steel electrodes. Subsequently, the cell was inserted for $1 \mathrm{~h}$ in the jacketed chamber in order to subject the samples to the different temperature and relative humidity combinations. Afterwards, EIS analysis was conducted in a potentiostatic mode (frequency interval of $1-10^{7} \mathrm{~Hz}$, amplitude of $0.5 \mathrm{~V}$ ) through the Bode analyzer tool of the STEMlab ${ }^{\mathrm{TM}} 125-14$ board by Red Pitaya. Three measurements for each sample were surveyed to guarantee a certain reliability of the results. The collected Bode diagrams were firstly converted to 
the corresponding Nyquist plots and then fitted with the appropriate equivalent circuit in ZView $^{\circledR}$, a dedicated software by Scribner Associates Inc. Specifically, a modified Randles cell was chosen for this purpose [23]. It consisted of an overall ohmic resistance $\left(R_{S}\right)$ in series with an RC element. This element displays the internal resistance $\left(R_{i}\right)$ in parallel with a constant phase element (CPE) [23-25], which is the main difference between a modified and a regular Randles cell, the latter being characterized by an ideal capacitor. However, systems in which porosity and roughness of the electrode/electrolyte interface are relevant are intrinsically not ideal; hence, their equivalent circuit requires a CPE to properly describe the corresponding depressed Nyquist arcs. In a generic Nyquist plot, $R_{S}$ corresponds to the intercept at high frequencies with the real impedance axis and accounts for ohmic losses, whereas the internal resistance of a material $\left(R_{i}\right)$ is represented by the diameter of the semicircle. Experimental values of $R_{i}$ were extrapolated from the Nyquist plots and used to derive the proton conductivity $\sigma\left(\mathrm{S} \mathrm{cm}^{-1}\right)$ of the investigated membranes, expressed by the second Ohm's law (Equation (3)):

$$
\sigma\left(\mathrm{S} \mathrm{cm}^{-1}\right)=\frac{1}{\rho}=\frac{\mathrm{d}}{\mathrm{R}_{\mathrm{I}} \cdot \mathrm{w} \cdot \mathrm{t}}
$$

The involved quantities are the resistivity $\rho(\Omega \mathrm{cm})$, the spacing between the metal electrodes $\mathrm{d}(\mathrm{cm})$, the sample width $\mathrm{w}(\mathrm{cm})$ and the sample thickness $\mathrm{t}(\mathrm{cm})$.

\section{Results and Discussion}

\subsection{Morphological and Microstructural Characterization}

The thermograms obtained from TGA are shown in Figure 1. Pristine GO was characterized by three main weight losses at an increasing temperature. The first one, which occurred below $100{ }^{\circ} \mathrm{C}$ and was about $15 \%$, was associated with the removal of physically adsorbed water on the hydrophilic groups of GO planes [18,26]. The second one (about $25 \%$ ) was detected close to $200{ }^{\circ} \mathrm{C}$ and may have referred to the decomposition of labile oxygenated functionalities (i.e., carboxyl, epoxide, hydroxyl and carbonyl groups), accompanied by the release of gaseous $\mathrm{CO}_{x}$ by-products $[27,28]$. The third step, resulting in a loss of approximately $35 \%$, was instead recognized above $550{ }^{\circ} \mathrm{C}$ and could be related to the disruption of the graphitic planes of GO as a consequence of the high temperature level [18].

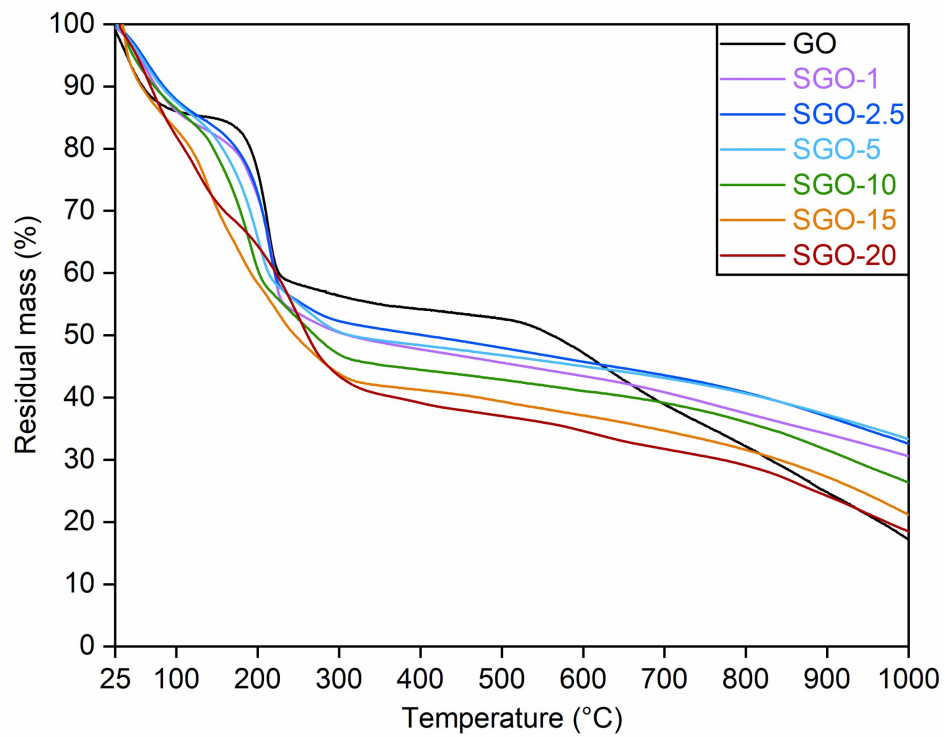

Figure 1. Thermograms of as-prepared SGO-X and benchmark GO membranes. Data of GO, SGO-1 and SGO-20 were reproduced with permission from [14]. 
Concerning the sulfonated samples, SGO-1, SGO-2.5, SGO-5 and, partly, SGO-10, displayed very similar trends to that of the pure material. However, some slight differences could be observed. In particular, a more pronounced loss of oxygenated groups (almost $30 \%$ ) was noticed at about $150^{\circ} \mathrm{C}$; therefore, at a temperature level lower than that of GO. In addition, a further weight reduction of nearly $6 \%$ was recorded above $250{ }^{\circ} \mathrm{C}$, which was not perceptible in the virgin material. These two losses may be ascribed to the stability of the introduced sulfonic groups, which could vary depending on their position in the GO framework [29]. The moieties weakly bonded to the carbonaceous structure could probably be removed below $200{ }^{\circ} \mathrm{C}$, whereas the ones able to form strong enough interactions may account for the second stage of mass drop. The latter was particularly pronounced (close to $11 \%$ ) in SGO-10, which may suggest a more effective sulfonation with respect to membranes prepared with lower acid-to-GO molar ratios.

Contrarily, SGO-15 and SGO-20 exhibited a nearly continuous weight decrease in the $100-250^{\circ} \mathrm{C}$ interval. The overlapping of the two previously discussed mass loss stages could be explained by an enhanced hydrophilic character of those samples, which potentially derived from a greater content of sulfonic groups and determined a larger amount of trapped water [18]. Moreover, their total mass loss in the investigated temperature range was higher compared to the other specimens, probably due to a reduced thermal stability caused by the high acid content. Hence, SGO-10 seemed to maintain the best thermal performance among the highly sulfonated samples, with a moderate mass loss in the temperature interval of interest for a possible fuel cell application and a residual mass larger than the benchmark GO.

ATR-FTIR spectra of the SGO-X membranes are displayed in Figure 2, together with the reference GO; they were acquired in order to check differences in the distribution and intensity of the contributions of functional groups. Considering the extreme complexity of the investigated systems and that the structure of GO has not yet been unanimously established, the following analysis has to be intended as purely qualitative. Starting from GO, the broad band (a) between 3700 and $2800 \mathrm{~cm}^{-1}$ could be assigned to the stretching vibration of $-\mathrm{OH}$ groups into various functional groups [14,30]. Specifically, three primary contributions could be detected at 3700, 3400 and $3200 \mathrm{~cm}^{-1}$, referable to $-\mathrm{OH}$ groups into hydroxyl, carboxyl functionalities and adsorbed water, respectively [14]. Several GO characteristic bands could be recognized at lower wavenumbers. The small contribution detected at (b) $1818 \mathrm{~cm}^{-1}$ could be attributed to $\mathrm{C}=\mathrm{O}$ stretching in anhydride groups. The one centered at (c) $1729 \mathrm{~cm}^{-1}$ could be associated with the stretching of $\mathrm{C}=\mathrm{O}$ from carboxyl and carbonyl groups. The band centered at (d) $1619 \mathrm{~cm}^{-1}$ could be related to the O-H bending in adsorbed water [31]. The oneI) between 1400 and $1300 \mathrm{~cm}^{-1}$ could be assigned to the $\mathrm{C}-\mathrm{OH}$ stretching in carboxyl groups and to the bending of $\mathrm{O}-\mathrm{H}$ into hydroxyl, carboxyl and phenol moieties. The contribution (f) between 1300 and $1200 \mathrm{~cm}^{-1}$ could mainly refer to the stretching vibration of -COC- from epoxide groups and, secondly, to other moieties such as ethers, esters and phenol ones [31,32]. Finally, two other bands could be identified at about (g) $1051 \mathrm{~cm}^{-1}$ and (h) $981 \mathrm{~cm}^{-1}$. The former could be related to the stretching of $\mathrm{C}-\mathrm{OH}$ bonds in hydroxyl moieties, whereas the latter could be attributed to the stretching of $\mathrm{C}-\mathrm{O}$ from unstable groups, typically lactols and peroxides [14].

SGO-X spectra exhibited some dissimilarities from the one of pristine GO. The contribution at (i) $1580 \mathrm{~cm}^{-1}$, which could be attributed to the stretching vibration of $\mathrm{C}=\mathrm{C}$ bonds in $\mathrm{sp}^{2}$-hybridized regions [32,33], seemed to progressively increase in intensity, with respect to the adjacent (d) band, while raising the acid-to-GO molar ratio. A possible explanation is the interaction of sulfuric acid with weaker oxygenated functionalities, which were removed with a consequent partial restoration of graphitic domains. Such a phenomenon appeared to be accompanied by the partial loss of hydroxyl groups, whose contribution at (a) 3700-3400 $\mathrm{cm}^{-1}$ was less intense. Reynosa-Martínez et al. [34] proposed a leaching effect as the main mechanism for the re-establishment of graphitic double bonds due to the action of sulfuric acid, mainly involving the $\mathrm{C}-\mathrm{OH}$ groups on the basal planes of $\mathrm{GO}$. Conversely, $\mathrm{C}=\mathrm{O}$ and $-\mathrm{COOH}$ functionalities were reported as difficult to reduce, given the 
high activation energy of the corresponding reactions. Other variations from pure GO were detected at wavenumbers lower than $1500 \mathrm{~cm}^{-1}$. A small rise in the band centered roughly at (j) $1150 \mathrm{~cm}^{-1}$ could be observed. Such a trend could be partially ascribed to the stretching of the $\mathrm{O}=\mathrm{S}=\mathrm{O}$ bonds in sulfonic groups $\left(-\mathrm{SO}_{3} \mathrm{H}\right)[14,35]$, albeit other functionalities could influence its intensity and width. Similarly, the band arising at (k) $880-870 \mathrm{~cm}^{-1}$ could be related to the stretching of $\mathrm{S}-\mathrm{O}$ in sulfinic $\left(-\mathrm{SO}_{2} \mathrm{H}\right)$ and sulfonic groups $[14,36]$. A growth in the intensity of these bands with respect to the adjacent $(\mathrm{g})$ mode could be appreciated at higher acid-to-GO molar ratios, suggesting a higher functionalization degree fostered by a larger sulfuric acid content.

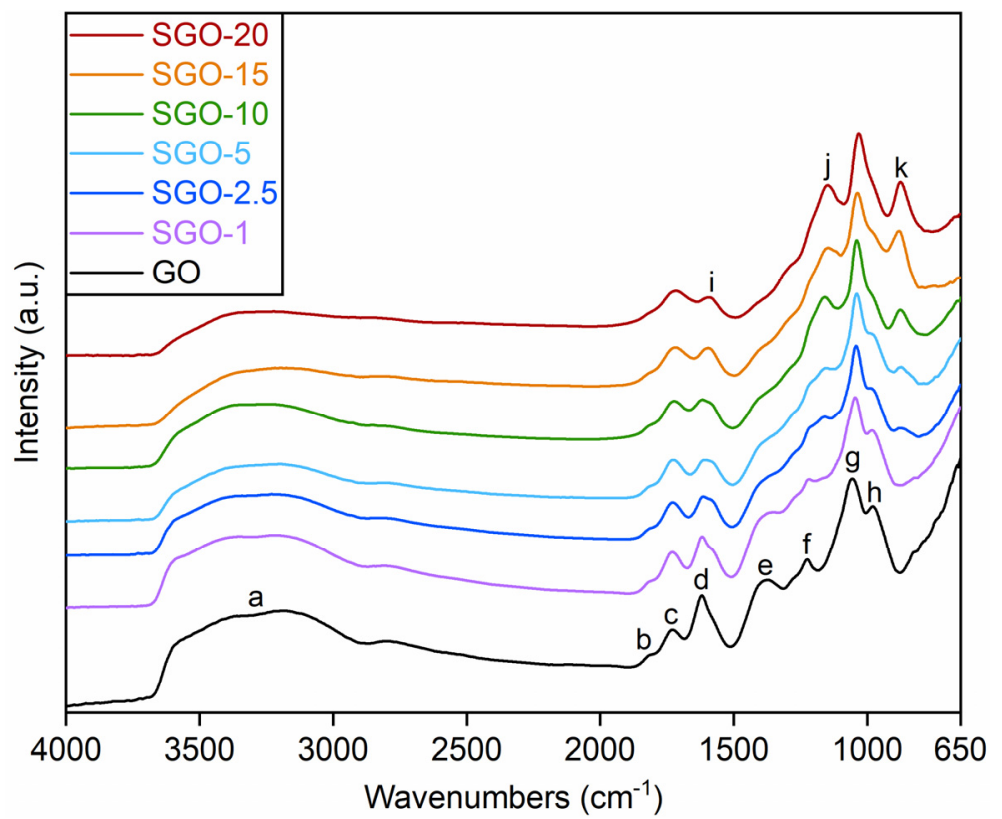

Figure 2. ATR-FTIR spectra of as-prepared SGO-X and benchmark GO membranes.

In parallel to these observations, one could notice the attenuation of baI (e) $1300-1400 \mathrm{~cm}^{-1}$ and (h), about $981 \mathrm{~cm}^{-1}$, which were recorded for pure GO. This phenomenon could be explained by assuming the removal of a fraction of the less stable lactol, peroxide and carboxyl groups due to the sulfonation process. Such a result may once again indicate the possible reduction caused by the acid when added in large quantities.

Raman spectra of the SGO-X samples and benchmark GO were collected in Figure 3. All spectra were characterized by two clearly recognizable bands. The first one, centered at about $1350 \mathrm{~cm}^{-1}$, is commonly referred to as the $\mathrm{D}$ band and derives from the structural disorder of the material. This vibrational mode was virtually absent in the crystalline graphite, which showed a high degree of order fostered by the $\mathrm{sp}^{2}$-hybridized carbons. On the contrary, GO-based materials possessed impurities due to the oxidation process, and so regions rich in carbons covalently bonded with O-bearing groups, which were generally assessed as the main contributions to the prominent $\mathrm{D}$ band [2,37]. The second band, located roughly at $1600 \mathrm{~cm}^{-1}$, is indicated as the $\mathrm{G}$ band [38]. It is related to the presence of graphitic domains within the GO structure [39] and its intensity grows with higher concentrations of conjugated and doubly bonded carbon atoms. A slight fading and broadening of the $\mathrm{G}$ band could be noticed moving from the virgin $\mathrm{GO}$ to the sulfonated samples, probably related to a partial amorphization of GO due to the interaction with the sulfonating species. 


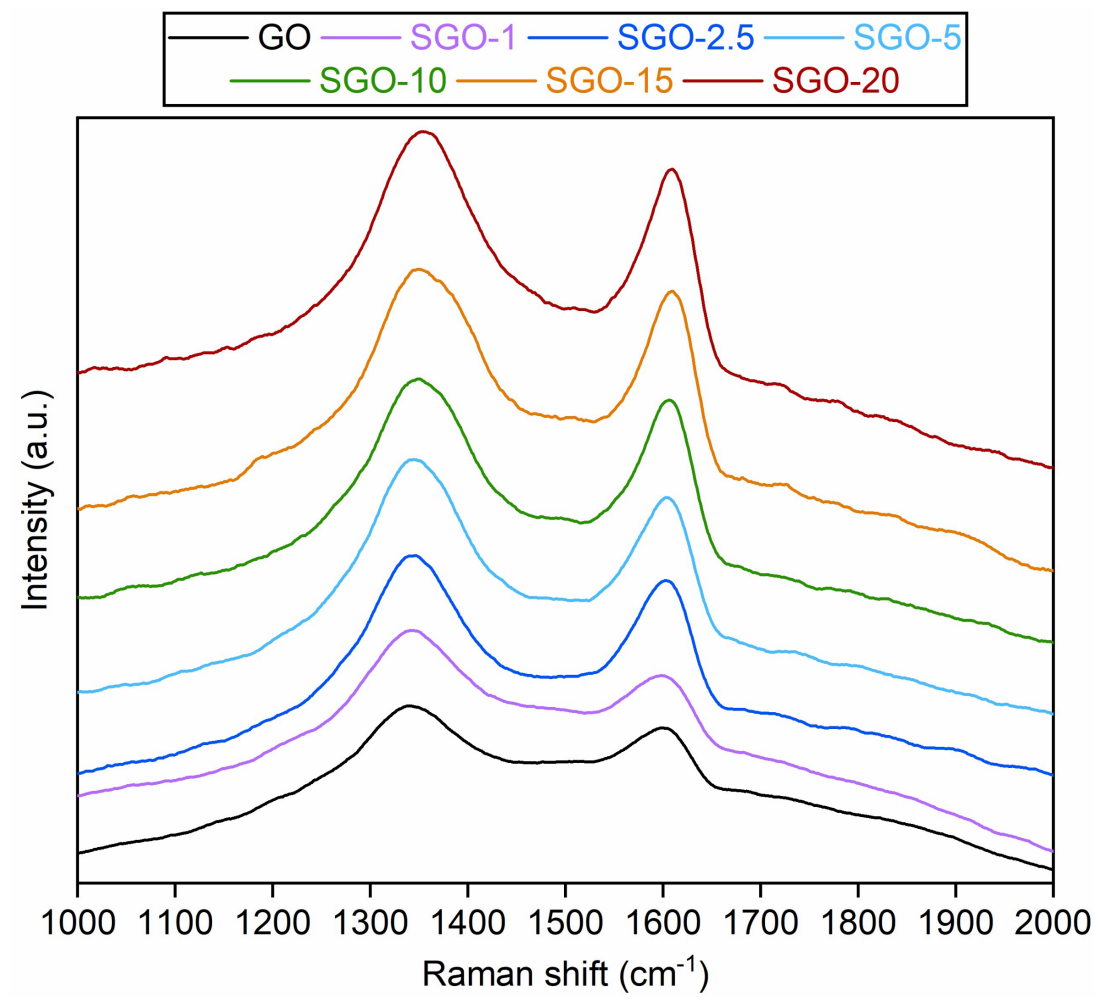

Figure 3. Raman spectra of the as-prepared SGO-X and benchmark GO membranes.

The ratio between the $\mathrm{D}$ and $\mathrm{G}$ band intensities $\left(\mathrm{I}_{\mathrm{D}} / \mathrm{I}_{\mathrm{G}}\right)$ could be deemed as a good parameter to estimate the degree of defectiveness in GO layers [2], albeit an interdependence of the $I_{D} / I_{G}$ values and the excitation laser energy should be considered [37]. The $I_{D} / I_{G}$ results for the investigated samples are reported in Table 2. The values seemed to lower with the increase in the acid-to-GO molar ratio. Such a trend could again hint the expansion of graphite-like zones in the membranes prepared with a high sulfuric acid content, as a consequence of the previously mentioned leaching effect. The minimum $\mathrm{I}_{\mathrm{D}} / \mathrm{I}_{\mathrm{G}}$ value, registered for SGO-15, could indicate that an acid-to-GO ratio greater than 10 started to have a detrimental effect on the $\mathrm{sp}^{3}$-hybridized carbon framework, leading to a partial reconstitution of $\mathrm{sp}^{2}$ domains. On the contrary, the higher result derived for SGO-20 could imply that functionalization issues occurred at the greatest sulfuric acid loading.

Table 2. Raman band positions and intensity ratios of the as-prepared SGO-X samples and benchmark GO.

\begin{tabular}{cccc}
\hline Sample & $\begin{array}{c}\text { D Band Position } \\
\left(\mathbf{c m}^{-\mathbf{1}} \mathbf{)}\right.\end{array}$ & $\begin{array}{c}\text { G Band Position } \\
\left(\mathbf{c m}^{-\mathbf{1}}\right)\end{array}$ & D/G Intensity Ratio \\
\hline GO & 1340 & 1599 & $1.53 \pm 0.06$ \\
SGO-1 & 1344 & 1598 & $1.60 \pm 0.03$ \\
SGO-2.5 & 1347 & 1602 & $1.36 \pm 0.08$ \\
SGO-5 & 1345 & 1604 & $1.41 \pm 0.02$ \\
SGO-10 & 1350 & 1606 & $1.08 \pm 0.01$ \\
SGO-15 & 1349 & 1609 & $0.98 \pm 0.03$ \\
SGO-20 & 1353 & 1609 & $1.29 \pm 0.13$ \\
\hline
\end{tabular}

The diffractograms acquired for the analyzed SGO-X and reference GO membranes at $30,60,120{ }^{\circ} \mathrm{C}$ and in the cooled state are illustrated in Figure 4 . The corresponding interlayer distances, derived from Equation (1), are listed in Table 3. Starting from the results obtained at $30{ }^{\circ} \mathrm{C}$ (Figure $4 \mathrm{a}$ ), a well-defined reflection was detected for all the specimens at a diffraction angle between $11.5^{\circ}$ and $14.5^{\circ}$. Such a range was much different 
from that of graphite $\left(22-23^{\circ}\right)$, inasmuch the presence of oxygenated functionalities in the GO framework induced a larger distance between adjacent layers [2,40,41]. Except for SGO-1, whose sulfuric acid content was not sufficient to provoke a deviation from GO, the increase in the acid-to-GO molar ratio involved reflections shifted to lower diffraction angles that were equivalent to higher interlayer distances. This trend could be interpreted as a consequence of the presence of sulfonic acid groups [17,41]. Nonetheless, SGO-20 proved a lowered interplanar distance with respect to SGO-15 $(0.85 \mathrm{~nm}$ and $0.88 \mathrm{~nm}$, respectively). Such an outcome could be attributed to a lower functionalization efficiency and, therefore, to less $-\mathrm{SO}_{3} \mathrm{H}$ groups introduced on $\mathrm{GO}$ basal planes.

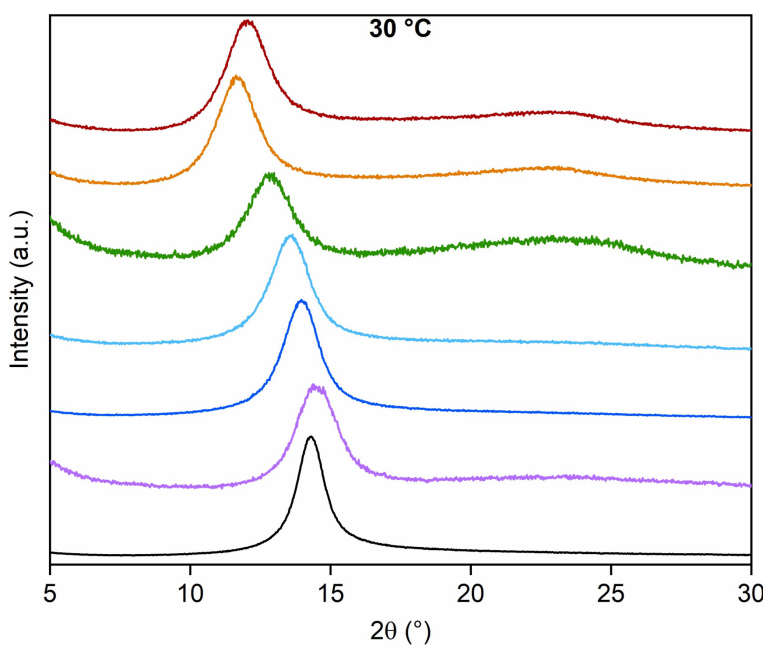

(a)

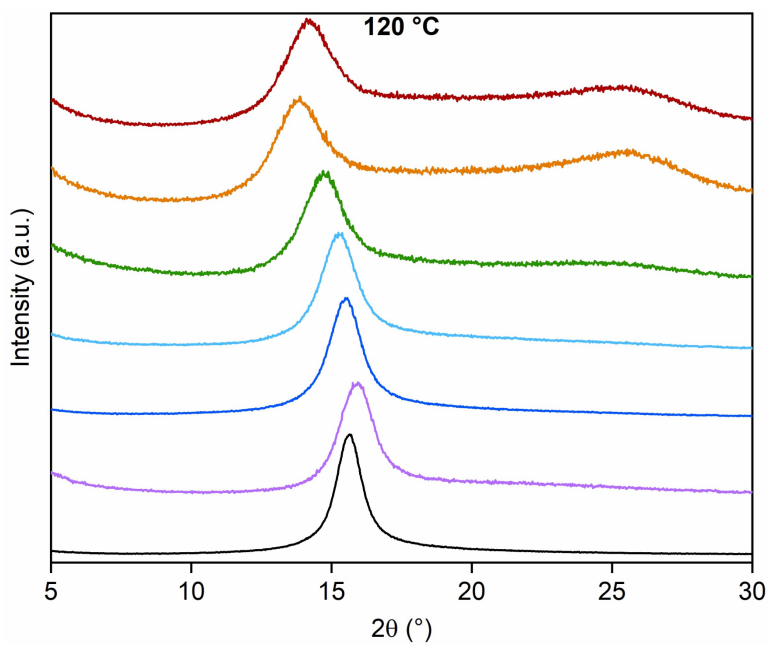

(c)

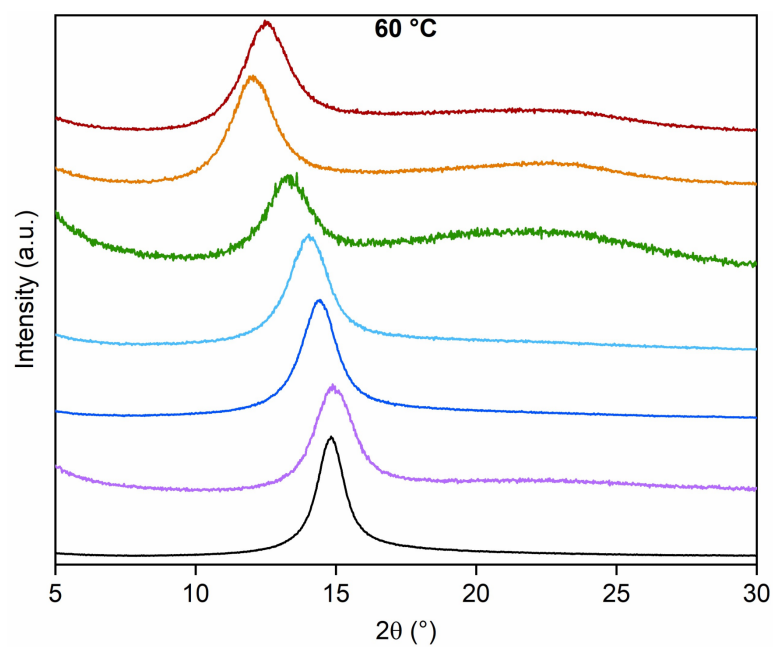

(b)

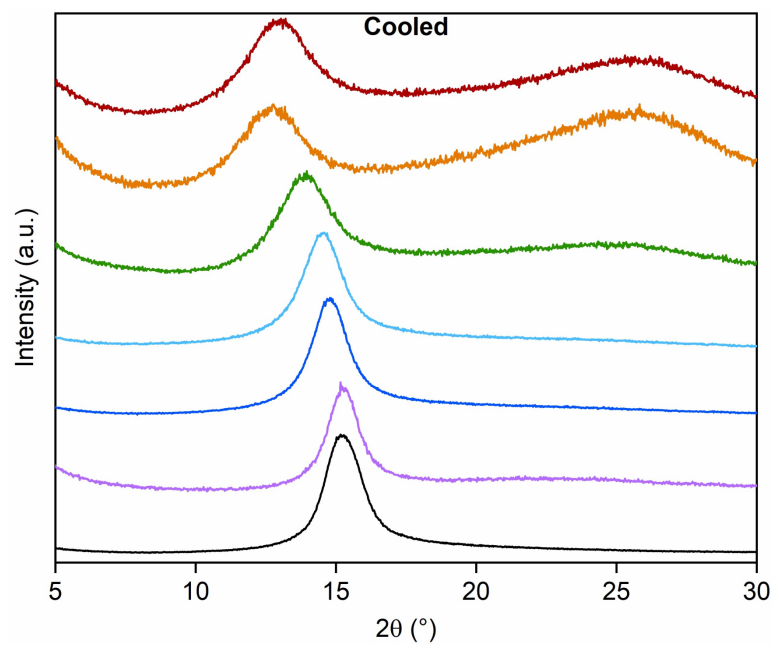

(d)

Figure 4. Diffractograms of the as-prepared SGO-X and benchmark GO membranes at (a) $30{ }^{\circ} \mathrm{C}$, (b) $60{ }^{\circ} \mathrm{C}$, (c) $120^{\circ} \mathrm{C}$ and (d) cooled state. 
Table 3. Interplanar distance of the as-prepared SGO-X and benchmark GO membranes at different temperatures, computed via Bragg's law.

\begin{tabular}{ccccc}
\hline & \multicolumn{4}{c}{ Temperature $\left({ }^{\circ} \mathbf{C}\right)$} \\
\cline { 2 - 5 } Sample & $\mathbf{3 0}$ & $\mathbf{6 0}$ & $\mathbf{1 2 0}$ & $\mathbf{3 0}$ (Cooled) \\
\cline { 2 - 5 } & \multicolumn{4}{c}{ Interplanar Distance (nm) } \\
\hline GO & 0.72 & 0.69 & 0.66 & 0.68 \\
SGO-1 & 0.71 & 0.69 & 0.65 & 0.68 \\
SGO-2.5 & 0.74 & 0.71 & 0.67 & 0.70 \\
SGO-5 & 0.75 & 0.73 & 0.68 & 0.71 \\
SGO-10 & 0.79 & 0.76 & 0.70 & 0.74 \\
SGO-15 & 0.88 & 0.85 & 0.74 & 0.81 \\
SGO-20 & 0.85 & 0.83 & 0.73 & 0.78 \\
\hline
\end{tabular}

The characteristic GO reflection moved towards higher diffraction angles with the increase in the experimental temperature (range $12-15^{\circ}$ at $60^{\circ} \mathrm{C}$ in Figure $4 \mathrm{~b}$, range $13.5-16^{\circ}$ at $120^{\circ} \mathrm{C}$ in Figure $4 \mathrm{c}$ ), leading to lower interlayer spacing for all the examined membranes. A slight thermal reduction with the loss of unstable O-bearing functional groups could be hypothesized. Hydroxyl groups with a low binding energy have been reported to dissociate even at room temperature [27,33], while some carboxyl moieties are supposed to be removed at about $100-150{ }^{\circ} \mathrm{C}$ [42]. This phenomenon could be seen as a sort of preliminary step of the mass loss measured approaching $200{ }^{\circ} \mathrm{C}$ during thermogravimetric analyses (Figure 1). The cooled condition (Figure 4d) appeared to strengthen the previous interpretation, since the related interplanar distance values were intermediate with respect to those at $60^{\circ} \mathrm{C}$ and $120^{\circ} \mathrm{C}$. On the one hand, the larger interplanar distance in comparison to the ones extrapolated at $120^{\circ} \mathrm{C}$ was probably caused by the re-adsorption of humidity within GO layers. On the other, the lower values in comparison to the ones observed at $60{ }^{\circ} \mathrm{C}$ and $30^{\circ} \mathrm{C}$ could confirm the slight thermal reduction in the studied materials.

Another evidence of the modifications having occurred at $120^{\circ} \mathrm{C}$ could be the rise in the flat and broad reflection near $22-27^{\circ}$ in the diffractograms of SGO-15 and SGO-20. This interval was similar to the typical diffraction angle range of crystalline graphite, equivalent to a stacking distance of about $0.34 \mathrm{~nm}[2,43]$. The reflection was even more evident in the cooled state, as if high-temperature levels induced permanent structural alterations on these samples. As already deduced from ATR-FTIR (Figure 2) and Raman (Figure 3) spectra, the membranes characterized by high acid loadings could already be prone to a transition towards a graphitic structure; ergo, the thermal effect could be facilitated.

Figure 5 and Figure S1 collect the surface images captured through scanning electron microscopy for all the as-prepared samples. Two different magnifications were analyzed, i.e., $100 \times$ (Figure 5) and $1000 \times$ (Figure S1), so as to obtain a more detailed view of possible morphological changes resulting from the functionalization process. The surfaces of SGO-X samples were rather homogenous altogether and, compared to pristine GO (Figure 5a), they did not show significant modifications brought by the addition of sulfuric acid. Regardless, they appeared slightly more wrinkled with respect to the smoother surface of GO, even in the case of SGO-1 (Figure 5b). This characteristic could confirm the occurrence of some morphological alteration even at the lowest acid-to-GO molar ratio. According to ReynosaMartínez et al. [34], wrinkles can be generated by an increase in the number of oxygenated functionalities, which induce tensions in the network. Therefore, the undulation arising on the SGO-X surfaces could have perhaps been provoked by the interaction with sulfuric acid that enriched pure GO with further O-bearing moieties. Whether they simply were $-\mathrm{SO}_{3} \mathrm{H}$ groups or a chemical transition from $\mathrm{sp}^{2}$ - to $\mathrm{sp}^{3}$-hybridized regions with the formation of new $\mathrm{C}-\mathrm{O}$ bonds [44] is yet to be cleared up. 


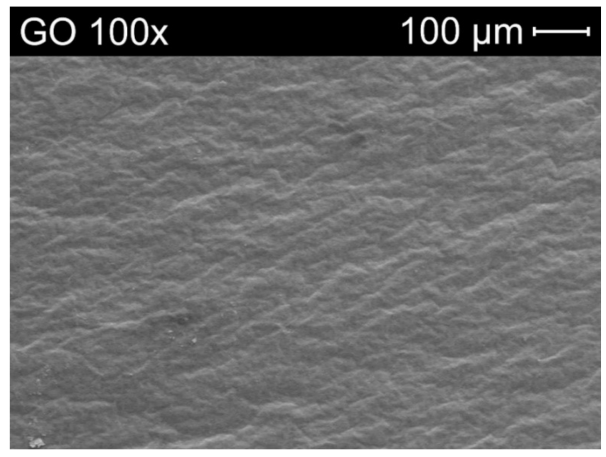

(a)

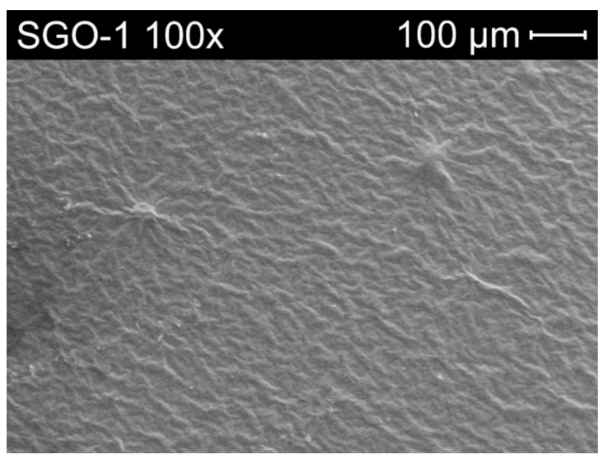

(b)

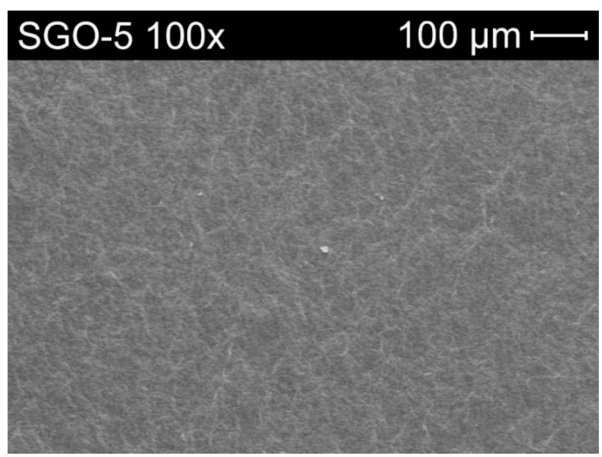

(d)

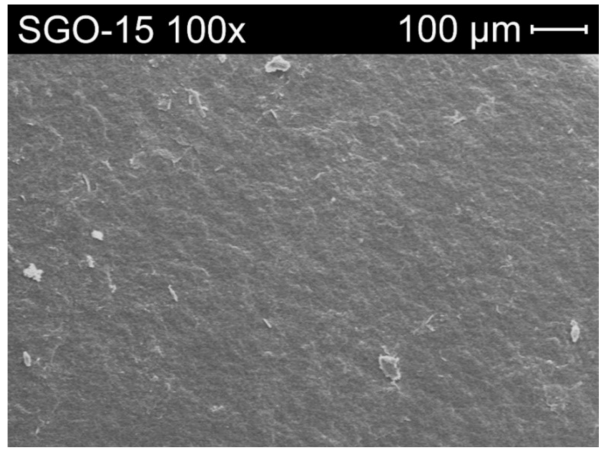

(f)

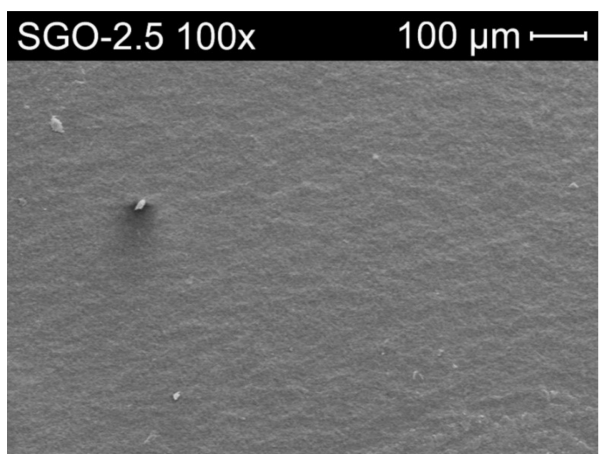

(c)

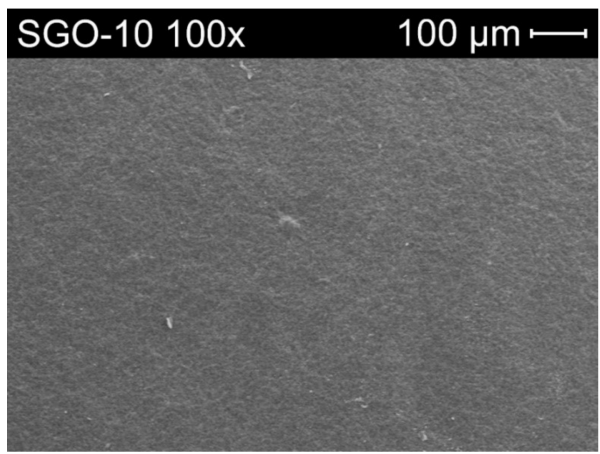

(e)

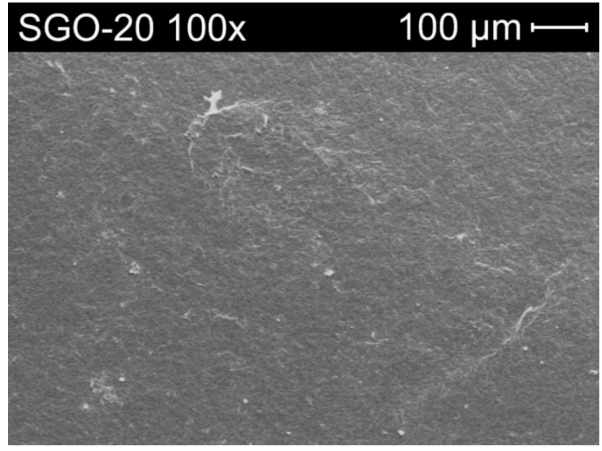

(g)

Figure 5. SEM images at 100× magnification of: (a) pure GO; (b) SGO-1; (c) SGO-2.5; (d) SGO-5; (e) SGO-10; (f) SGO-15; (g) SGO-20.

The semi-quantitative elemental data derived from EDX spectra are summarized in Figure 6. The benchmark GO carbon-to-oxygen atomic percentage ratio $(2.03 \pm 0.03)$ 
appeared to be consistent with the typical one indicated in the literature (1.5-2.5) [45]. The $1.65 \mathrm{wt}$.\% of sulfur (S) recorded for the virgin material had to be ascribed to the use of sulfur-containing species in the synthesis process $[19,46]$. As expected, the proposed functionalization method affected the composition of the GO framework. A reduction in the weight percentage of carbon could be observed, as well as a rise in sulfur and oxygen contents even at the lowest sulfonation degree (SGO-1). Such an outcome suggested a successful introduction of $-\mathrm{SO}_{3} \mathrm{H}$ groups by means of sulfuric acid.

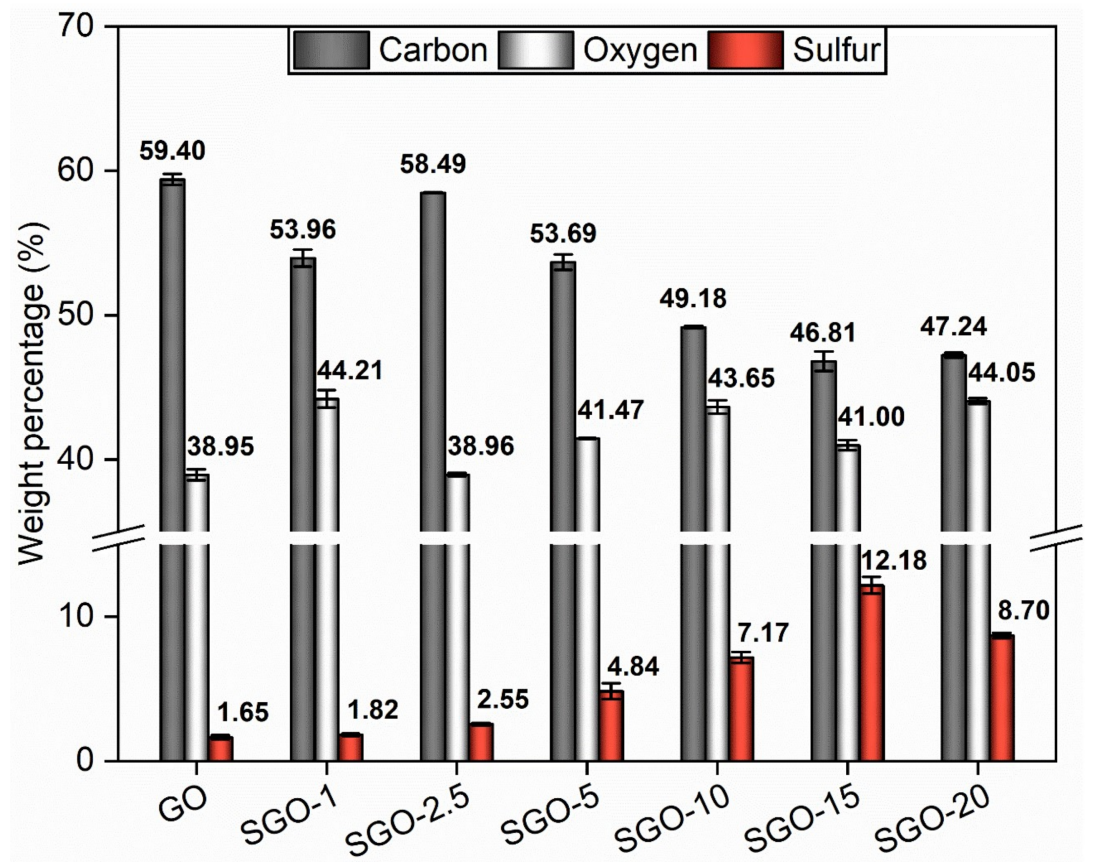

Figure 6. EDX spectroscopy results of the as-prepared SGO-X and benchmark GO membranes.

Nevertheless, SGO-2.5, SGO-15 and SGO-20 elemental analyses allowed to determine some considerations. First of all, the manufacturing stages should still be optimized, inasmuch SGO-2.5 appeared more analogous to GO than to SGO-1, in terms of the C/O ratio. Regarding SGO-15, the amount of employed acid probably surpassed a threshold value over which a partial reduction in GO layers was promoted, as previously discussed. Consequently, some oxygenated groups were likely to be removed and the overall oxygen content diminished. Such a result agreed with the ATR-FTIR spectrum (Figure 2) of this sample, as well as with its $\mathrm{I}_{\mathrm{D}} / \mathrm{I}_{\mathrm{G}}$ ratio (Table 2), which turned out to be the lowest; thus, this indicated the partial restoration of ordered graphitic domains. A further increase in the acid-to-GO ratio (SGO-20) led to a growth in the oxygen weight percentage and a decrease in that of sulfur, approaching values that were comparable to those of SGO-10. One might attribute this outcome to a less effective functionalization, which caused fewer sulfonic acid groups to be introduced on the $G O$ planes. The $\mathrm{I}_{\mathrm{D}} / \mathrm{I}_{\mathrm{G}}$ ratio derived for SGO-20 $(1.29 \pm 0.13)$ and the analysis of XRD patterns (Figure 4$)$ could support this interpretation, since the pre-existing $\mathrm{sp}^{3}$-hybridized carbons seemed to remain dominant with respect to the $\mathrm{sp}^{2}$-hybridized ones, similarly to pristine GO [47].

\subsection{Ion Exchange Capacity}

The IEC was determined with the purpose of understanding how the presence of sulfonic acid groups influenced the ability of GO to carry ions. The results, obtained via Equation (2) after the titration procedure explained in Section 2.4, are shown in Figure 7. All the fabricated SGO-X membranes outperformed both Nafion ${ }^{\circledR} 212$ and pristine GO. A value of $0.71 \pm 0.03$ meq $\mathrm{g}^{-1}$ was measured for benchmark Nafion ${ }^{\circledR} 212$. It was slightly lower than the one reported in the literature, which was about 0.90 meq $\mathrm{g}^{-1}$ [48-50]. Such an outcome may be the consequence of the preliminary treatment in the oven at 
$60{ }^{\circ} \mathrm{C}$, which could have damaged the most superficial $-\mathrm{SO}_{3} \mathrm{H}$ groups. Nevertheless, one should consider that the drying phase was crucial to remove traces of water trapped in the material and obtain reliable measurements of the dry weight. The recorded value for pure GO $\left(0.76 \pm 0.16\right.$ meq $\left.^{-1}\right)$ was practically equivalent to that of Nafion ${ }^{\circledR} 212$ and did not excessively differ from the values surveyed in a preceding work by the authors [14] and found in the literature [1,12].

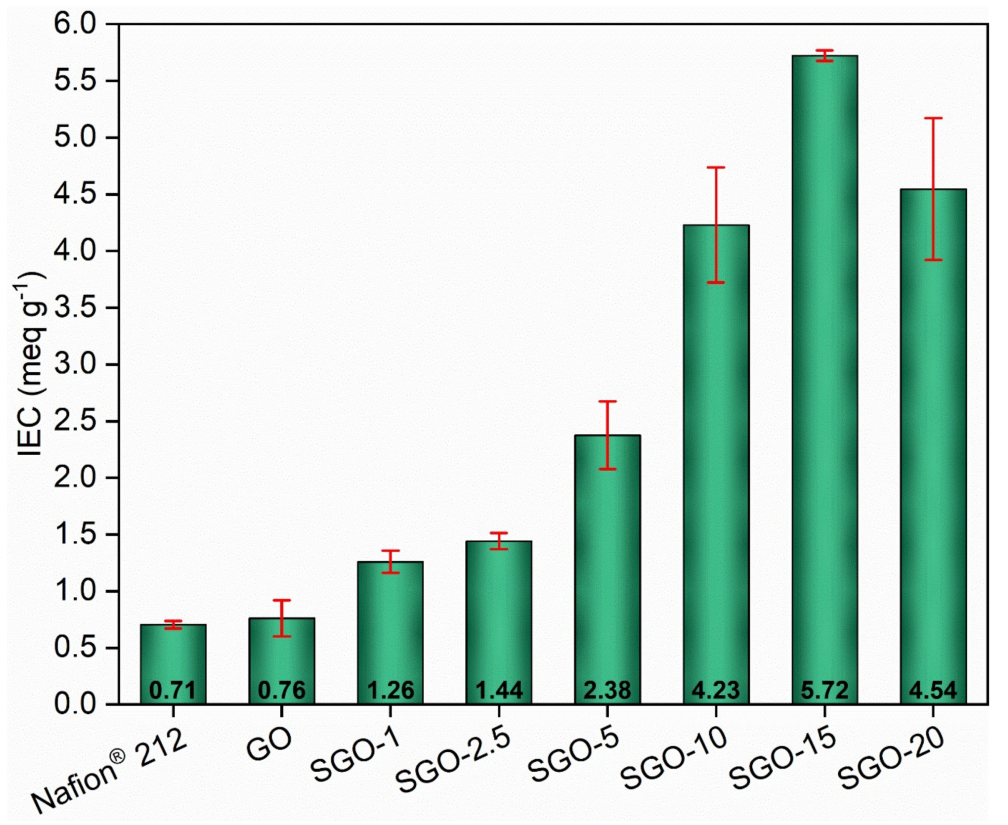

Figure 7. IEC values of the as-prepared SGO-X membranes compared to benchmark GO and Nafion ${ }^{\circledR} 212$.

The sulfonated membranes demonstrated an upward IEC tendency parallel to the increase in the acid-to-GO molar ratio. SGO-1, whose IEC value was $1.26 \pm 0.10 \mathrm{meq} \mathrm{g}^{-1}$, disclosed an almost two-fold improvement with respect to GO. Once again, an actual modification of the original structure was indicated, even at the minimum sulfuric acid amount. SGO-2.5 was comparable with SGO-1, whereas large improvements were recorded for SGO$5\left(2.38 \pm 0.30 \mathrm{meq} \mathrm{g}^{-1}\right)$, SGO-10 $\left(4.23 \pm 0.51 \mathrm{meq}^{-1}\right)$ and SGO-15 $\left(5.72 \pm 0.05 \mathrm{meq} \mathrm{g}^{-1}\right)$. SGO-15 exhibited the highest IEC among all tested samples, with an eight-fold enhancement over pure GO. The additional increase in the acid-to-GO molar ratio up to 20 in SGO-20 (4.54 \pm 0.63 meq $\left.^{-1}\right)$ did not guarantee comparable IEC values, but the result was still noteworthy despite the previously hypothesized less effective functionalization. Such considerations were reinforced by the EDX elemental analysis (Figure 6), since the evolution of the IEC performance appeared to reflect the trend of the measured sulfur content, which could be associated, by analogy, with the amount of sulfonic acid groups effectively inserted on the GO layers.

\subsection{Proton Conductivity}

Electrochemical impedance spectroscopy permitted the derivation of proton conductivity values for all the as-prepared SGO-X samples, as well as for the reference Nafion ${ }^{\circledR} 212$ and pure GO. The results obtained at both high (95\%) and medium (42\%) RH are displayed in Figure 8. In general, proton conductivity increased with temperature. This trend was expected, since the energy barrier to overcome to trigger protons' mobility was more easily surpassed at higher temperatures [40]. The SGO-X membranes produced the best performances at high RH (Figure 8a), thanks to the influence of polar S-bearing groups that were able to gather a considerable amount of water and to form ionic clusters that encouraged proton diffusion [35]. The only exception was SGO-1, whose low functionalization degree prevented a clear improvement with respect to GO. The virgin material showed the overall 
worst results, since its oxygenated functionalities could have been insufficient to guarantee an adequate proton conductivity [1], despite the good water sorption ability demonstrated from the water uptake (WU) tests (Section S2). The SGO-2.5 results were superimposable to the ones of Nafion ${ }^{\circledR} 212$. One should notice that the extrapolated values for the commercial material were larger than the typical results reported in the literature, which were about $0.1 \mathrm{~S} \mathrm{~cm}^{-1}$ [1,51-53]. Such an inconsistency could be ascribed to the condensation of water droplets on the surface of the stainless-steel electrodes during the tests, which could have altered the final measurements. Nonetheless, the overall trend could still be considered reliable, given that the experiments were conducted on all membrane samples with the same test conditions. A further increase in the acid-to-GO molar ratio up to 15 was accompanied by a continuous improvement of the proton conductivity up to values of $1-3 \mathrm{~S} \mathrm{~cm}^{-1}$. Then, SGO-20 displayed slightly worse results in the $20-60{ }^{\circ} \mathrm{C}$ interval. This behavior strongly agreed with the previously discussed EDX (Figure 6) and IEC (Figure 7) outcomes, as well as with those of WU tests (Section S2). The SGO-10 trend was the most consistent among all investigated specimens, with a proton conductivity surpassing $1 \mathrm{~S} \mathrm{~cm}^{-1}$. Moreover, the restrained values' variability could hint the good homogeneity of this sample. It is necessary to specify that the sulfonated membranes exhibited substantially higher outcomes than the ones reported in the literature for innovative proton conductors [13,51,52,54,55]. A possible explanation is the presence of small traces of sulfuric acid trapped in between the stacked GO layers, which could have led to an overestimation of the real conductivity value.

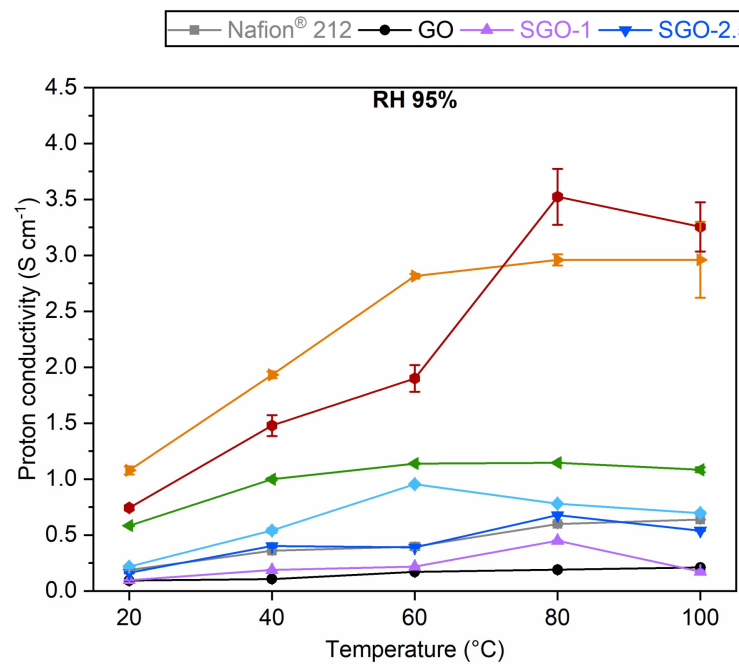

(a)

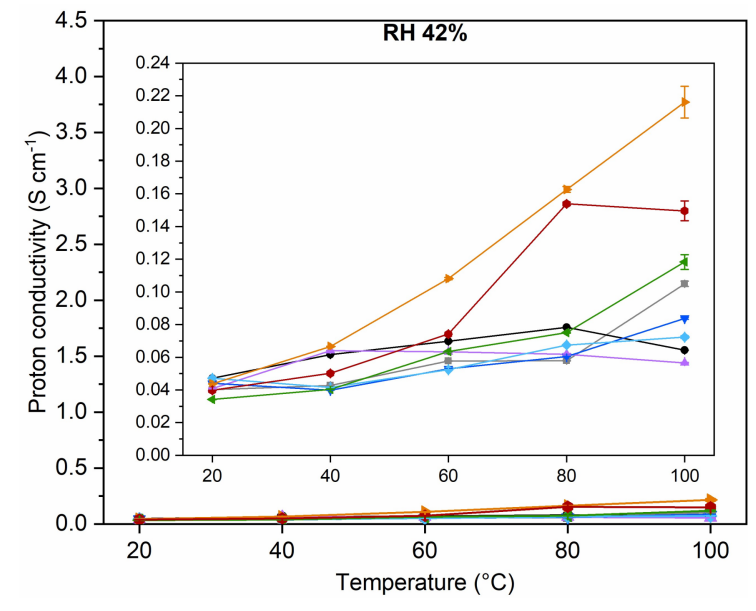

(b)

Figure 8. Proton conductivity values at (a) $95 \% \mathrm{RH}$ and (b) $42 \% \mathrm{RH}$ of the as-prepared SGO-X membranes compared to the benchmark GO and Nafion ${ }^{\circledR} 212$ in the interval of $20-100{ }^{\circ} \mathrm{C}$.

The considerations determined for high $\mathrm{RH}$ results could be extended to medium RH ones as well (Figure 8 b), albeit the proton conductivity was drastically reduced due to the partial inhibition of the water-mediated conduction mechanism [40]. In fact, it is believed that the Grotthuss mechanism dominates when the availability of hydrated pathways is reduced [18]. Differently from the high RH case, pure GO proved a better performance with respect to Nafion ${ }^{\circledR} 212$, in accordance with the higher WU values observed in medium humidification conditions (Section S2). The samples characterized by lower sulfonation degrees (SGO-1, SGO-2.5, SGO-5) demonstrated quite similar proton conductivity values, following the observations acquired from the water uptake evaluation. A substantial enhancement was detected for SGO-10, especially at high temperatures. In such conditions, it outperformed both Nafion ${ }^{\circledR} 212$ and pristine GO with a proton conductivity of $0.118 \pm 0.005 \mathrm{~S} \mathrm{~cm}^{-1}$. An additional performance growth was registered for 
SGO-15, whereas SGO-20 was not able to reach the same outcomes, most likely because of the speculated loss in the sulfonation effectiveness.

\section{Conclusions}

Self-standing sulfonated graphene oxide (SGO-X) membranes were prepared from virgin GO through a simple and easily reproducible method relying on the vacuum filtration of sulfuric acid-modified dispersions and low-temperature oven-drying of the deposits. Six acid-to-GO molar ratios were investigated to study different functionalization degrees.

The extensive morphological and microstructural characterization performed on the samples suggested the effectiveness of the proposed procedure. The actual modification of the GO structure with the introduction of sulfonic acid groups was supposed even at low acid loadings from the analysis of ATR-FTIR spectra, XRD patterns and EDX compositional results. The infrared spectroscopy allowed us to detect different bands in SGO-X samples with respect to pure $\mathrm{GO}$, which were attributed to the stretching vibrations of sulfur-bearing moieties. The interplanar distance derived from diffractograms grew with the acid-to-GO molar ratio, due to the presence of sulfonic acid groups. The sulfur content in the SGO-X samples underwent a continuous growth parallel to the employed sulfuric acid amount up to SGO-15.

Several evidences of loss in the functionalization efficiency were detected at an acidto-GO molar ratio of 20 by Raman spectroscopy, EDX measurements and XRD analysis, which suggested a smaller quantity of $-\mathrm{SO}_{3} \mathrm{H}$ groups introduced on $\mathrm{GO}$ planes and the partial restoration of graphitic domains, as also observed from the more intense stretching vibration of $\mathrm{C}=\mathrm{C}$ bonds in ATR-FTIR spectra.

The functional characterization of the SGO-X samples allowed a comparison with pure GO and commercial Nafion ${ }^{\circledR} 212$. The sulfonated materials demonstrated an improved ion exchange capacity, up to values ranging from 4 to $5 \mathrm{meq} \mathrm{g}^{-1}$ for SGO-10, SGO-15 and SGO-20. Proton conductivity values were extrapolated from EIS measurements. The trend with respect to temperature and relative humidity agreed with the results obtained from the IEC tests. The samples characterized by a high acid-to-GO molar ratio provided the best outcomes at both high and medium RH.

In light of the results obtained, SGO-10 can be regarded as the most promising GOderived material among the presented ones. It proved a less widespread presence of graphite-like domains, an adequate homogeneity and a high ion exchange capacity of $4.23 \pm 0.51 \mathrm{meq} \mathrm{g}^{-1}$. Furthermore, it displayed a stable proton conductivity at high humidity and a better value than GO and Nafion ${ }^{\circledR} 212$ at $100{ }^{\circ} \mathrm{C}$ and $42 \% \mathrm{RH}$. Additional research should be devoted to more thoroughly investigating the effects of the proposed functionalization procedure on both the structure and properties of the membranes, by means of additional morphological (e.g., X-ray photoelectron spectroscopy) and functional (e.g., tensile strength tests) analyses. The aim is to optimize both the composition and structural stability of these materials, in order to achieve a successful characterization of their in situ behavior in a functioning fuel cell.

Supplementary Materials: The following supporting information can be downloaded, Section S1: Scanning electron microscopy, Section S2: Assessment of water uptake, Table S1: Water uptake results at $95 \% \mathrm{RH}$ of the as-prepared SGO-X membranes compared to reference GO and Nafion ${ }^{\circledR}$ 212, Table S2: Water uptake results at $42 \%$ RH of the as-prepared SGO-X membranes compared to reference GO and Nafion ${ }^{\circledR}$ 212. Reference [56] is cited in Supplementary Materials.

Author Contributions: Conceptualization, A.B.P. and S.L.; methodology, S.L.; formal analysis, A.B.P., M.D.V. and A.B.; investigation, A.B.P. and A.B.; resources, E.M., R.L.K. and G.D.; writing-original draft preparation, A.B.P. and M.D.V.; writing-review and editing, S.L., E.M., R.L.K. and G.D.; visualization, A.B.P., M.D.V. and S.L.; supervision, E.M., R.L.K. and G.D.; funding acquisition, R.L.K. and G.D. All authors have read and agreed to the published version of the manuscript. 
Funding: This work was funded by the European Institute of Innovation and Technology (EIT) RawMaterials (Berlin, Germany), project ADMA2 - practical training between academia and the industry during doctoral studies, grant number 18252.

Institutional Review Board Statement: Not applicable.

Informed Consent Statement: Not applicable.

Data Availability Statement: Not applicable.

Acknowledgments: The authors wish to thank Auli Turkki (Environmental and Chemical Engineering Research Unit) and Marcin Selent (Centre for Material Analysis) of the University of Oulu, Finland, for their crucial role in organizing and performing X-ray diffraction experiments. Deep gratitude is also expressed towards Luigi Brambilla (Organic Functional and Nanostructured Materials Laboratory) of Politecnico di Milano, Italy, who helped the authors in acquiring and analyzing ATR-FTIR and Raman spectra.

Conflicts of Interest: The authors declare no conflict of interest.

Sample Availability: Samples of the compounds are available from the authors.

\section{References}

1. Jiang, Z.; Shi, Y.; Jiang, Z.J.; Tian, X.; Luo, L.; Chen, W. High performance of a free-standing sulfonic acid functionalized holey graphene oxide paper as a proton conducting polymer electrolyte for air-breathing direct methanol fuel cells. J. Mater. Chem. A 2014, 2, 6494-6503. [CrossRef]

2. Claramunt, S.; Varea, A.; López-Díaz, D.; Velázquez, M.M.; Cornet, A.; Cirera, A. The Importance of Interbands on the Interpretation of the Raman Spectrum of Graphene Oxide. J. Phys. Chem. C 2015, 119, 10123-10129. [CrossRef]

3. Tian, Y.; Yu, Z.; Cao, L.; Zhang, X.L.; Sun, C.; Wang, D.-W. Graphene oxide: An emerging electromaterial for energy storage and conversion. J. Energy Chem. 2021, 55, 323-344. [CrossRef]

4. Tang, Q.; Zhou, Z.; Chen, Z. Graphene-related nanomaterials: Tuning properties by functionalization. Nanoscale 2013, 5, 4541-4583. [CrossRef]

5. Smith, A.T.; LaChance, A.M.; Zeng, S.; Liu, B.; Sun, L. Synthesis, properties, and applications of graphene oxide/reduced graphene oxide and their nanocomposites. Nano Mater. Sci. 2019, 1, 31-47. [CrossRef]

6. Latorrata, S.; Cristiani, C.; Basso Peressut, A.; Brambilla, L.; Bellotto, M.; Dotelli, G.; Finocchio, E.; Gallo Stampino, P.; Ramis, G. Reduced Graphene Oxide Membranes as Potential Self-Assembling Filter for Wastewater Treatment. Minerals 2020, 11, 15. [CrossRef]

7. Gontrani, L.; Pulci, O.; Carbone, M.; Pizzoferrato, R.; Prosposito, P. Detection of Heavy Metals in Water Using Graphene Oxide Quantum Dots: An Experimental and Theoretical Study. Molecules 2021, 26, 5519. [CrossRef]

8. Garg, B.; Bisht, T.; Ling, Y.-C. Graphene-Based Nanomaterials as Heterogeneous Acid Catalysts: A Comprehensive Perspective Molecules 2014, 19, 14582-14614. [CrossRef]

9. Jia, P.; Du, X.; Chen, R.; Zhou, J.; Agostini, M.; Sun, J.; Xiao, L. The Combination of 2D Layered Graphene Oxide and 3D Porous Cellulose Heterogeneous Membranes for Nanofluidic Osmotic Power Generation. Molecules 2021, 26, 5343. [CrossRef]

10. Chee, W.K.; Lim, H.N.; Harrison, I.; Chong, K.F.; Zainal, Z.; Ng, C.H.; Huang, N.M. Performance of Flexible and Binderless Polypyrrole/Graphene Oxide/Zinc Oxide Supercapacitor Electrode in a Symmetrical Two-Electrode Configuration. Electrochim. Acta 2015, 157, 88-94. [CrossRef]

11. Cong, R.; Park, H.-H.; Jo, M.; Lee, H.; Lee, C.-S. Synthesis and Electrochemical Performance of Electrostatic Self-Assembled Nano-Silicon@N-Doped Reduced Graphene Oxide/Carbon Nanofibers Composite as Anode Material for Lithium-Ion Batteries. Molecules 2021, 26, 4831. [CrossRef] [PubMed]

12. Hou, H.; Hu, X.; Liu, X.; Hu, W.; Meng, R.; Li, L. Sulfonated graphene oxide with improved ionic performances. Ionics (Kiel) 2015, 21, 1919-1923. [CrossRef]

13. Gagliardi, G.G.; Ibrahim, A.; Borello, D.; El-Kharouf, A. Composite Polymers Development and Application for Polymer Electrolyte Membrane Technologies-A Review. Molecules 2020, 25, 1712. [CrossRef] [PubMed]

14. Basso Peressut, A.; Latorrata, S.; Gallo Stampino, P.; Dotelli, G. Development of self-assembling sulfonated graphene oxide membranes as a potential proton conductor. Mater. Chem. Phys. 2021, 257, 123768. [CrossRef]

15. Zarrin, H.; Higgins, D.; Jun, Y.; Chen, Z.; Fowler, M. Functionalized graphene oxide nanocomposite membrane for low humidity and high temperature proton exchange membrane fuel cells. J. Phys. Chem. C 2011, 115, 20774-20781. [CrossRef]

16. Chien, H.-C.C.; Tsai, L.-D.D.; Huang, C.-P.P.; Kang, C.Y.; Lin, J.-N.N.; Chang, F.-C.C. Sulfonated graphene oxide/Nafion composite membranes for high-performance direct methanol fuel cells. Int. J. Hydrogen Energy 2013, 38, 13792-13801. [CrossRef]

17. Li, C.; Huang, N.; Jiang, Z.; Tian, X.; Zhao, X.; Xu, Z.L.; Yang, H.; Jiang, Z.J. Sulfonated holey graphene oxide paper with SPEEK membranes on its both sides: A sandwiched membrane with high performance for semi-passive direct methanol fuel cells. Electrochim. Acta 2017, 250, 68-76. [CrossRef] 
18. Vinothkannan, M.; Kim, A.R.; Gnana Kumar, G.; Yoo, D.J. Sulfonated graphene oxide/Nafion composite membranes for high temperature and low humidity proton exchange membrane fuel cells. RSC Adv. 2018, 8, 7494-7508. [CrossRef]

19. Graphenea Graphene Oxide, Product Datasheet. Available online: https://cdn.shopify.com/s/files/1/0191/2296/files/ Graphenea_GO_4mgmL_Datasheet_202109.pdf?v=1632927913 (accessed on 10 January 2022).

20. Dreyer, D.R.; Park, S.; Bielawski, C.W.; Ruoff, R.S. The chemistry of graphene oxide. Chem. Soc. Rev. 2010, 39, 228-240. [CrossRef]

21. Yadav, R.; Subhash, A.; Chemmenchery, N.; Kandasubramanian, B. Graphene and Graphene Oxide for Fuel Cell Technology. Ind. Eng. Chem. Res. 2018, 57, 9333-9350. [CrossRef]

22. Latorrata, S.; Basso Peressut, A.; Gallo Stampino, P.; Cristiani, C.; Dotelli, G. Preliminary study on the development of sulfonated graphene oxide membranes as potential novel electrolytes for PEM fuel cells. ECS Trans. 2018, 86, 347-356. [CrossRef]

23. Yuan, X.-Z.; Song, C.; Wang, H.; Zhang, J. Electrical fundamentals. In Electrochemical Impedance Spectroscopy in PEM Fuel Cells; Springer: London, UK, 2010; pp. 39-93. [CrossRef]

24. Yuan, X.-Z.; Song, C.; Wang, H.; Zhang, J. Impedance and its corresponding electrochemical processes. In Electrochemical Impedance Spectroscopy in PEM Fuel Cells; Springer: London, UK, 2010; pp. 95-138. [CrossRef]

25. Yuan, X.-Z.; Song, C.; Wang, H.; Zhang, J. EIS equivalent circuits. In Electrochemical Impedance Spectroscopy in PEM Fuel Cells; Springer: London, UK, 2010; pp. 139-192. [CrossRef]

26. Alharbi, T.M.D.; Harvey, D.; Alsulami, I.K.; Dehbari, N.; Duan, X.; Lamb, R.N.; Lawrance, W.D.; Raston, C.L. Shear stress mediated scrolling of graphene oxide. Carbon 2018, 137, 419-424. [CrossRef]

27. Eigler, S.; Dotzer, C.; Hirsch, A.; Enzelberger, M.; Müller, P. Formation and decomposition of $\mathrm{CO}_{2}$ intercalated graphene oxide. Chem. Mater. 2012, 24, 1276-1282. [CrossRef]

28. Chen, W.; Yan, L.; Bangal, P.R. Preparation of graphene by the rapid and mild thermal reduction of graphene oxide induced by microwaves. Carbon 2010, 48, 1146-1152. [CrossRef]

29. Zhao, L.; Li, Y.; Zhang, H.; Wu, W.; Liu, J.; Wang, J. Constructing proton-conductive highways within an ionomer membrane by embedding sulfonated polymer brush modified graphene oxide. J. Power Sources 2015, 286, 445-457. [CrossRef]

30. Rattana, T.; Chaiyakun, S.; Witit-Anun, N.; Nuntawong, N.; Chindaudom, P.; Oaew, S.; Kedkeaw, C.; Limsuwan, P. Preparation and characterization of graphene oxide nanosheets. Procedia Eng. 2012, 32, 759-764. [CrossRef]

31. Lee, D.C.; Yang, H.N.; Park, S.H.; Kim, W.J. Nafion/graphene oxide composite membranes for low humidifying polymer electrolyte membrane fuel cell. J. Memb. Sci. 2014, 452, 20-28. [CrossRef]

32. Iwan, A.; Caballero-Briones, F.; Malinowski, M.; Filapek, M.; Tazbir, I.; Guerrero-Contreras, J.; Kamaraj, S.-K. Graphene oxide influence on selected properties of polymer fuel cells based on Nafion. Int. J. Hydrogen Energy 2017, 42, 15359-15369. [CrossRef]

33. Acik, M.; Mattevi, C.; Gong, C.; Lee, G.; Cho, K.; Chhowalla, M.; Chabal, Y.J. The role of intercalated water in multilayered graphene oxide. ACS Nano 2010, 4, 5861-5868. [CrossRef]

34. Reynosa-Martínez, A.C.; Gómez-Chayres, E.; Villaurrutia, R.; López-Honorato, E. Controlled reduction of graphene oxide using sulfuric acid. Materials 2021, 14, 59. [CrossRef]

35. Rahmanian, A.; Naji, L.; Javanbakht, M. The influence of sulfonation level on the electrochemical characteristics of Pt/rSGO as electrocatalyst for proton exchange membrane fuels cells. Solid State Ion. 2018, 326, 27-36. [CrossRef]

36. Fernandes, A.C.; Ticianelli, E.A. A performance and degradation study of Nafion 212 membrane for proton exchange membrane fuel cells. J. Power Sources 2009, 193, 547-554. [CrossRef]

37. Cançado, L.G.; Takai, K.; Enoki, T.; Endo, M.; Kim, Y.A.; Mizusaki, H.; Jorio, A.; Coelho, L.N.; Magalhães-Paniago, R.; Pimenta, M.A. General equation for the determination of the crystallite size La of nanographite by Raman spectroscopy. Appl. Phys. Lett. 2006, 88, 163106. [CrossRef]

38. López-Díaz, D.; López Holgado, M.; García-Fierro, J.L.; Velázquez, M.M. Evolution of the Raman Spectrum with the Chemical Composition of Graphene Oxide. J. Phys. Chem. C 2017, 121, 20489-20497. [CrossRef]

39. Kudin, K.N.; Ozbas, B.; Schniepp, H.C.; Prud'homme, R.K.; Aksay, I.A.; Car, R. Raman Spectra of Graphite Oxide and Functionalized Graphene Sheets. Nano Lett. 2008, 8, 36-41. [CrossRef] [PubMed]

40. Bayer, T.; Cunning, B.V.; Selyanchyn, R.; Daio, T.; Nishihara, M.; Fujikawa, S.; Sasaki, K.; Lyth, S.M. Alkaline anion exchange membranes based on $\mathrm{KOH}$-treated multilayer graphene oxide. J. Memb. Sci. 2016, 508, 51-61. [CrossRef]

41. Liu, Y.; Wang, J.; Zhang, H.; Ma, C.; Liu, J.; Cao, S.; Zhang, X. Enhancement of proton conductivity of chitosan membrane enabled by sulfonated graphene oxide under both hydrated and anhydrous conditions. J. Power Sources 2014, 269, 898-911. [CrossRef]

42. Pei, S.; Cheng, H.M. The reduction of graphene oxide. Carbon 2012, 50, 3210-3228. [CrossRef]

43. Stobinski, L.; Lesiak, B.; Malolepszy, A.; Mazurkiewicz, M.; Mierzwa, B.; Zemek, J.; Jiricek, P.; Bieloshapka, I. Graphene oxide and reduced graphene oxide studied by the XRD, TEM and electron spectroscopy methods. J. Electron Spectros. Relat. Phenom. 2014, 195, 145-154. [CrossRef]

44. Mkhoyan, K.A.; Contryman, A.W.; Silcox, J.; Stewart, D.A.; Eda, G.; Mattevi, C.; Miller, S.; Chhowalla, M. Atomic and electronic structure of graphene-oxide. Nano Lett. 2009, 9, 1058-1063. [CrossRef]

45. Araújo, M.P.; Soares, O.S.G.P.; Fernandes, A.J.S.; Pereira, M.F.R.; Freire, C. Tuning the surface chemistry of graphene flakes: New strategies for selective oxidation. RSC Adv. 2017, 7, 14290-14301. [CrossRef]

46. Hummers, W.S.; Offeman, R.E. Preparation of graphitic oxide. J. Am. Chem. Soc. 1958, 80, 1339. [CrossRef]

47. Eda, G.; Chhowalla, M. Chemically derived graphene oxide: Towards large-area thin-film electronics and optoelectronics. Adv. Mater. 2010, 22, 2392-2415. [CrossRef] [PubMed] 
48. Dai, H.; Zhang, H.; Luo, Q.; Zhang, Y.; Bi, C. Properties and fuel cell performance of proton exchange membranes prepared from disulfonated poly(sulfide sulfone). J. Power Sources 2008, 185, 19-25. [CrossRef]

49. Yuan, D.; Qin, Y.; Li, S.; Du, S.; Xu, Y.; Weng, Q.; Chen, P.; Chen, X.; An, Z. Enhanced performance of proton-conducting poly(arylene ether sulfone)s via multiple alkylsulfonated side-chains and block copolymer structures. J. Memb. Sci. 2021, 621, 118932. [CrossRef]

50. Ureña, N.; Pérez-Prior, M.T.; Levenfeld, B.; García-Salaberri, P.A. On the conductivity of proton-exchange membranes based on multiblock copolymers of sulfonated polysulfone and polyphenylsulfone: An experimental and modeling study. Polymers 2021, 13, 363. [CrossRef]

51. Sun, X.; Simonsen, S.C.; Norby, T.; Chatzitakis, A. Composite membranes for high temperature PEM fuel cells and electrolysers: A critical review. Membranes 2019, 9, 83. [CrossRef]

52. Lee, K.; Guiver, M.D. Fuel Cell Performance of Poly(arylene ether nitrile)s Containing Pendant Sulfonic Acid Groups under Reduced RH Conditions. In Electrochemical Society Meeting Abstracts 215; The Electrochemical Society, Inc.: Honolulu, HI, USA, 2009. [CrossRef]

53. Li, J.; Wu, H.; Cao, L.; He, X.; Shi, B.; Li, Y.; Xu, M.; Jiang, Z. Enhanced Proton Conductivity of Sulfonated Polysulfone Membranes under Low Humidity via the Incorporation of Multifunctional Graphene Oxide. ACS Appl. Nano Mater. 2019, 2, 4734-4743. [CrossRef]

54. Zhai, L.; Li, H. Polyoxometalate-Polymer Hybrid Materials as Proton Exchange Membranes for Fuel Cell Applications. Molecules 2019, 24, 3425. [CrossRef]

55. Vilela, S.M.F.; Salcedo-Abraira, P.; Gómez-Peña, A.; Trens, P.; Várez, A.; Salles, F.; Horcajada, P. Proton Conductive Zr-Phosphonate UPG-1-Aminoacid Insertion as Proton Carrier Stabilizer. Molecules 2020, 25, 3519. [CrossRef]

56. Doyle, M.; Rajendran, G. Perfluorinated membranes. In Handbook of Fuel Cells; John Wiley \& Sons, Ltd.: New York, NY, USA, 2010; pp. 1-45. [CrossRef] 